\title{
Assessing the Effect of Different Mortar Mixes on Strength of Burnt Clay Brick Masonry Wall
}

\author{
Owino Stephen, Dr. Kyakula Michael, Dr. Mugume Rodgers Bangi \\ Faculty of Engineering, Department of Civil and Building Engineering, \\ Kyambogo University, Uganda.
}

\begin{abstract}
The population of Uganda grew from $12.6 \mathrm{~m}$ in 1980 to $34.6 \mathrm{~m}$ in 2014 . This has been matched by an increase in housing demand. The estimated annual demand is 200,000 units per year. The National Housing and population census of 2014 showed that burnt clay bricks are the most commonly used walling material at $36.4 \%$ followed by mud and poles at $33.6 \%$. However, there is no data on the strength of burnt clay brick walls and the relationship between strength of bricks and that of mortar that would inform design. A survey of 24 Structural Engineering consultancy firms was carried and it was found that none of these design masonry walls made from burnt clay bricks. A survey of 102 sites revealed that the batching method employed was a bag of cement to a number of wheelbarrows. Thus a mix of one bag of cement to three wheel barrows would be specified as 1:3, yet the average volume of a wheel barrow is about $0.089 \mathrm{~m}^{3}$ and the volume of a $50 \mathrm{Kg}$ bag of cement is about $0.036 \mathrm{~m}^{3}$. Tests revealed that the water absorption of the bricks varied from $9.23 \%$ to $16.68 \%$. The strength of the bricks varied widely from $1.62 \mathrm{~N} / \mathrm{mm}^{2}$ to $8.49 \mathrm{~N} / \mathrm{mm}^{2}$. The source of sand used on most sites determined the source of sand used in making mortar cubes. The strength of mortar cubes varied from $17.8 \mathrm{~N} / \mathrm{mm}^{2}$ at $1: 3$ to $1.87 \mathrm{~N} / \mathrm{mm}^{2}$ at $1: 14$. Masonry walls of $1 \mathrm{~m}$ wide by $1 \mathrm{~m}$ high were constructed with mortar mixes to match those in the field and the walls were tested under compression. Tests revealed that mortar joints fail before bricks. The strength of the wall constructed varied from $1.85 \mathrm{~N} / \mathrm{mm}^{2}$ at $1: 7$ mortar mix to $1.49 \mathrm{~N} / \mathrm{mm}^{2}$ at $1: 14$ mortar mix. This was $69 \%$ to $77 \%$ of the designed wall strength. The failure of the mortar before bricks eases maintenance because mortar is more flexible and cracks in mortar tend to be smaller and easier to repair.
\end{abstract}

Key Words : Mortar mixes, Mortar Cube strength, Brick strength and Wall strength

\section{INTRODUCTION TO THE STUDY}

There has been a tremendous increase in Uganda's population growth rate from $1.2 \%$ in 1980 to $3 \%$ in 2014 leading to a population of 34.6 million people in 2014 from 12.6 million people in 1980, (UBOS). This has been characterized by growth in housing units from 2.6 million houses in 1980 to 7.34 million houses in 2014 with $75 \%$ of the population leaving in rural areas and $25 \%$ urban dwellers. The forecast showed an increase in population to 47 million people in 2025 and 63 million people in 2040 indicating an increase in demand of housing units to cater for the increased population, (UBOS, 2014). The estimated annual housing demand is 200,000 units per year. The 2014 housing and population census showed that houses with permanent walling materials constituted $43.7 \%$. It further showed that burnt clay brick walls were the most used walling material at $36.4 \%$ followed by mud and poles at
$33.6 \%$ as given in distribution of Household Walling Materials, (UBOS, 2014).

The purpose of cement in the mix of cement-lime - sand mortar is to unite coarse grained sand particles together, (Clark Deichler, 1936). The use of cement as a binder has greatly increased from 1.37 billion tons in 1994 to 3.7 billion tons in 2012, (Zainab Hashim Abbas, 2017). The evaluation of the mechanical properties of mortar by (Marcos Venicus, et.al., 2014), indicated that cement sand mortar is flexible, easy to work with and easy to repair. Hamid Eskandari (2017), revealed that the strength of mortar increased with age and depends on the class of cement. Francis M.Fernandes, (2009), found out that ordinary clay bricks were difficult to characterize due to the wide diversity of raw materials and the manufacturing process. Results revealed scattering compressive strength ranging between 1.5- $30 \mathrm{MPa}$ and this depended mostly on the water absorption rate of the burnt clay bricks. Konthesingha.C, (1985), investigated the effect of bond strength and compressive strength of ordinary clay bricks and standard bricks. Results revealed that standard bricks gave a higher tensile and shear strength compared to ordinary bricks and hence good bondage is evidenced with use of standard bricks "engineered bricks". Mosalam, et.al., (2009), found out that the interface between mortar and masonry units is the weakest link in the system and this depended entirely on properties and composition of the constituents.

Nassif Nazeer, (2018), revealed that the strength of masonry structures entirely depends on the thickness of the bed joint, height to thickness ratio in relation to mortar strength. Emeritus and Hendry, (2001), reviewed different types of masonry walls among which included those constructed of burnt clay bricks, concrete blocks and calcium silicate bricks where clay burnt masonry structures revealed a strength of about 100MPa for commercial buildings and between $20-40 \mathrm{MPa}$ for domestic buildings and 2.8 - 35MPa for concrete block structures.

This research was therefore set out to determine the mortar mix ratios used on construction sites around Kampala and to determine the mortar strength corresponding to mortar mix ratios commonly used around Kampala. It also sought to determine the strength of bricks used on sites around Kampala and thus establish strength of the wall in relation to mix ratios, brick strength and mortar strength 


\section{1 Materials tested}

\section{METHODOLOGY}

This research investigation, the following materials were tested in the assessment of the effect of different mortar ratios on the strength of burnt clay masonry walls

- Fine grained sand

- Course grained sand

- Mortar cubes

- Burnt clay bricks and

- Brick walls $1 \mathrm{~m}$ long x $1 \mathrm{~m}$ high x $0.2 \mathrm{~m}$ wide

\subsection{Tests carried out}

The following tests were carried out to ascertain the quality of the materials that were used in the construction of burnt clay brick masonry walls.

- Sieve analysis test on the sand samples

- Specific gravity and bulk density of the sand samples

- Water absorption on bricks

- Compressive strength of the mortar cubes

- Compressive strength of burnt clay bricks

- Compressive strength of the masonry wall structures

\section{RESULTS}

Mortar mixes

Table 1, Shows the mortar mixes used on 102 site

\begin{tabular}{|c|c|c|}
\hline $\begin{array}{c}\text { Field Mortar Ratios } \\
\text { (Bag:Wheelbarrows) }\end{array}$ & Number of sites & $\begin{array}{c}\text { Percentage } \\
\text { representation }\end{array}$ \\
\hline $1: 4$ & 47 & 46 \\
\hline $1: 5$ & 32 & 31 \\
\hline $1: 6$ & 16 & 16 \\
\hline $1: 3$ & 6 & 6 \\
\hline $1: 2$ & 1 & 1 \\
\hline & $\mathbf{1 0 2}$ & $\mathbf{1 0 0}$ \\
\hline
\end{tabular}

Table 1 , shows that $46 \%$ of the sampled sites uses one bag of cement of $50 \mathrm{Kg}$ to four wheel barrows full of sand,(1:4), $32 \%$ of the sites uses one bag of cement of $50 \mathrm{Kg}$ to five wheelbarrows full of sand, (1:5), 16\% uses one bag of cement of $50 \mathrm{Kg}$ to six wheel barrows full of sand, (1:6), $6 \%$ uses one bag of cement to three wheel arrows full of sand, (1:3) and $1 \%$ uses one bag of cement to two wheelbarrows full of sand, (1:2).

i. Of the 102 sites surveyed it was found that 76 sites used mortar mix proportions dictated by the site engineer while 26 sites revealed that this is dictated by the client.

ii. All the 102 sites revealed that they use cement: sand mortar. The mortar ratios used on the 102 sites are given in Table 1.

iii. The batching methods used on all 102 sites was number of cement bags to number of full wheelbarrows of sand.

iv. The volume of a $50 \mathrm{Kg}$ bag of sand was found to be $0.036 \mathrm{~m}^{3}$. And the average volume of different wheelbarrows used on 102 sites was $0.089 \mathrm{~m}^{3}$ when filled to the top of the wheelbarrow bucket as shown in Figure 1.

v. The level to which a wheel barrow is filled depended on the whims of workforce or the supervisors. There was no site where guidelines on the level of filling the wheel barrow was found. All sites revealed that the sand was heaped above the top of the wheel barrow bowel as shown in Figure 1.

vi. One bag of cement to three wheel barrows of sand is not actually $1: 3$ as the site engineers assessment but 1 : $(3 * 2.47)=: 7.42$, therefore tests carried out in this work used the commonly field observed mix proportion.

vii. The mix proportions used in the field are not appropriate to the strength intended since a wheel barrow of sand media is 2.47 times the volume of a cement bag.

viii. $59 \%$ of the sites indicated that they mix fine sand and coarse sand to make the sand media in the mortar, $32 \%$ of the sites use only coarse sand and $7 \%$ use only fine sand. Because $59 \%$ of the 102 sites use a combination of fine and coarse sand, the experiments were designed to use the same.

ix. Results of compressive strength of trial tests on individual mortar obtained from a mix of a single type of sand revealed that compressive strength of obtained from single sand type mixed with cement varied much with no consistency while results of the mix of the two sand type mixed with cement indicated consistency in the results as shown in Figure:2.

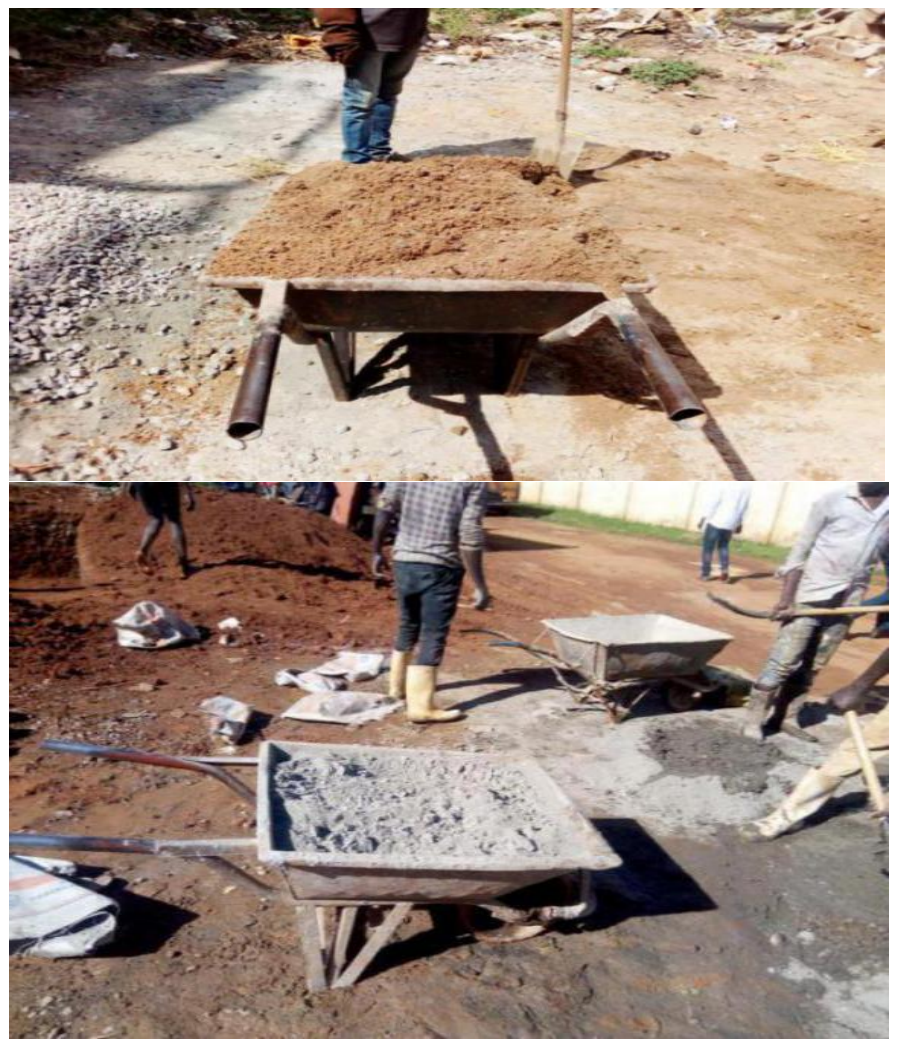

Figure 1: Wheel barrow full of sand and wheelbarrow of cement $(50 \mathrm{~kg}$ bag cement) 


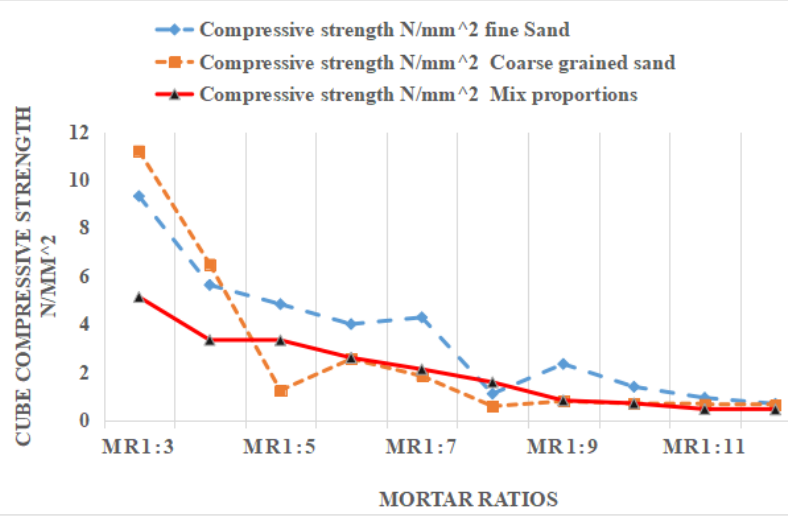

Figure: 2, shows a graph of compressive strength of mortar Vs mix

\section{Sand media used}

On all 102 sites the respondents explained that the site engineer determined the source of sand based on experience. Research found out that 59\% of the sites around Kampala used coarse sand extracted from Rwera mining site along Kampala - Masaka road and this was followed by Buwama sand at 16\%, Kapeeka sand at $12 \%$ and lastly Lake Victoria and Kamengo at $7 \%$.

\section{a) Sieve analysis test on coarse grained sand}

The sand for use in construction industry should meet the requirements with respect to grading, absence of organic matter and absence of excessive clay, according ASTM C136/C136M. Rwera sand was chosen to be used in this experiment because it is the most used sand. Figure:3, shows the results of the sieve analysis tests carried out on sand from Rwera mining site. Results revealed that the sand is well graded.

\section{Gradation curves for coarse grained sand}

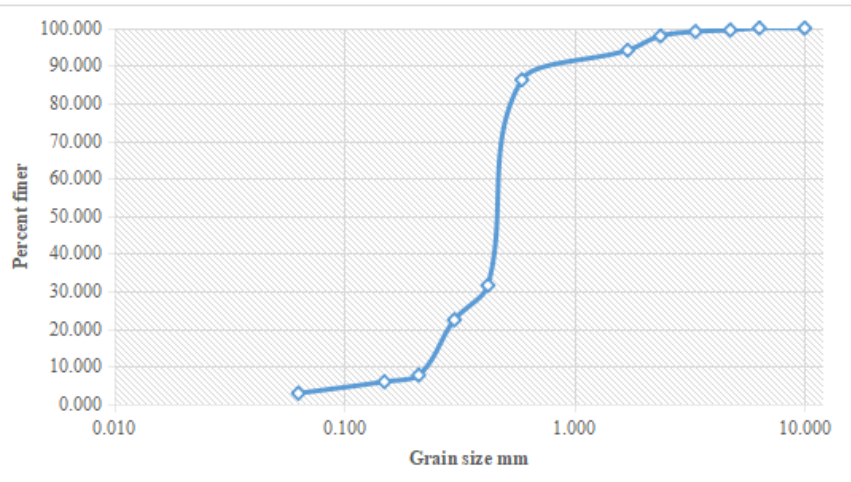

Figure : 3, Gradation curve for coarse grained sand

\section{b) . Sieve analysis test of fine grained sand}

A survey of 102 sites revealed varying sources of fine grained sand (locally called plaster sand) depending on the location of the site. This sand is usually extracted from the nearest valley to the sites. Considering Kampala Jinja road, 9 sites of the fifteen sample size used fine grained sand from Katosi, hence, its selection for use in this experiment. The results of the sieve analysis in Figure:4

\section{Gradation curves for fine grained sand}

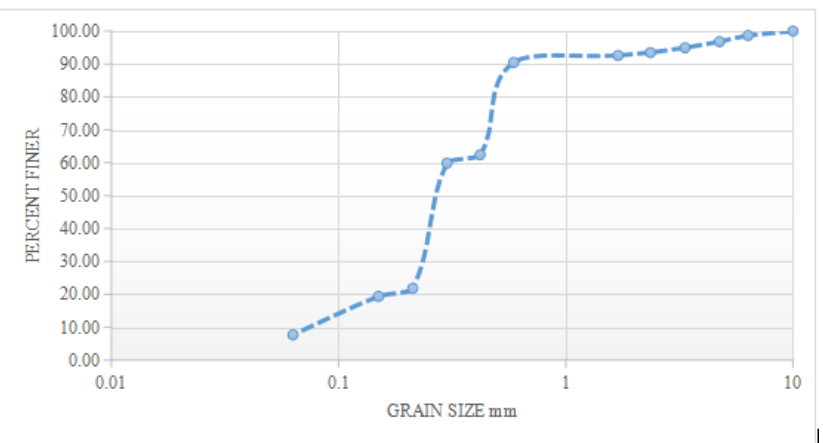

Figure: 4,Gradation curve for fine sand

c) Specific gravity test and bulk density test on sand media used

The results for specific gravity of the sand media was determined using pyconometer method in accordance with ASTM C 127-1993 and the bulk density test which was conducted in accordance to BS 812-2 (1995). Results from specific gravity test revealed that specific gravity for coarse grained sand is 2.73 and that of fine grained sand is 2.61 . This is within the range specified by IS : 2386 ( Part III )

\section{d) Cement}

The type of cement used on sites varied from site to site depending on the availability on the local market; this research found that $56 \%$ of the sites use $32.5 \mathrm{R}$ and $44 \%$ use $32.5 \mathrm{~N}$.

\section{e) Compressive strength of mortar Cubes}

In accordance to ASTM C109/C109M standard method for testing the compressive strength of cement mortar, a total of 36 mortar cubes were tested after 28 days of curing and their compressive strength recorded, these comprised of mortar ratios from 1:3, 1:4, 1:5, 1:6, 1:7, 1:8, 1:9, 1:10, $1: 11,1: 12,1: 13$ and $1: 14$, mortar ratios from $1: 7$ to $1: 14$ represented the commonly used corrected field mix proportions.

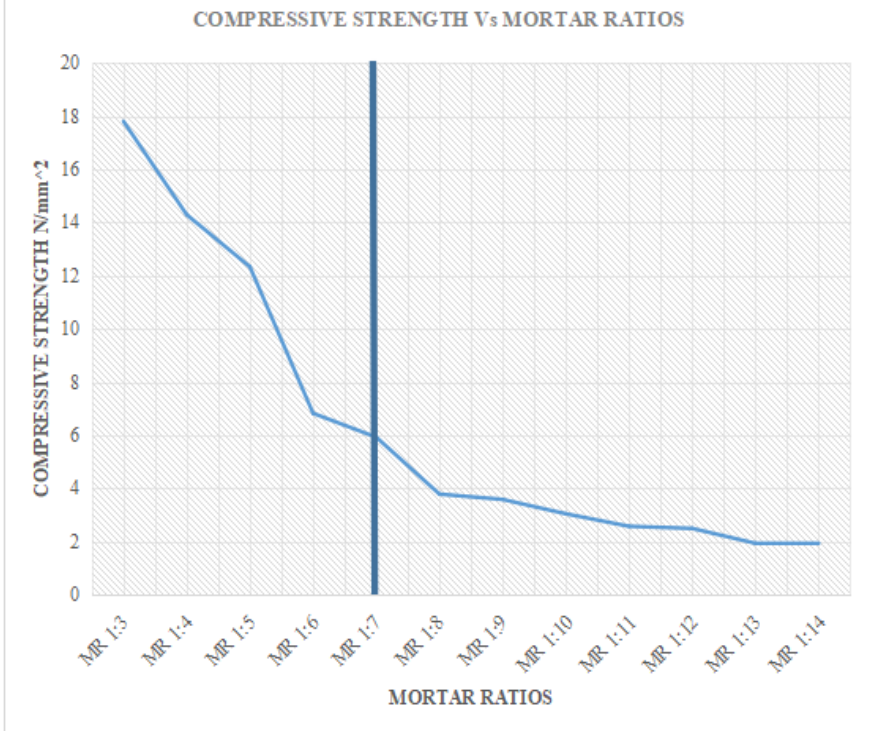

Figure: 5, Compressive strength of mortar cubes 
From Figure:5, the commonly used field observed mortar ratios are found to have a maximum strength of $6.82 \mathrm{~N} / \mathrm{mm}^{2}$ at mix proportion $1: 7$ and a minimum strength of $1.87 \mathrm{~N} / \mathrm{mm}^{2}$ at a mix proportion of $1: 14$. From field evaluation of batching methods, mix ratios less than 1:7 were not used.

\section{f) Bricks}

In this research study, burnt clay bricks from Hoima road were used due to its good properties and relatively moderate deviation in compressive strength

\section{i. Compressive strength of burnt clay bricks}

Results of compressive strength of bricks sourced from 35 construction sites along major roads joining Kampala metropolitan among showed that the average compressive strength of burnt clay bricks varied from $9.7 \mathrm{~N} / \mathrm{mm}^{2}$ to $1.6 \mathrm{~N} / \mathrm{mm}^{2}$

Table 2: Summary of the average compressive strength of burnt clay bricks from the major selected bricks

Table 2: Average compressive strength of burnt clay bricks

\begin{tabular}{l|ccccc}
\hline MAJOR ROADS & A1 & A2 & A3 & A4 & A5 \\
\hline Hoima road & 8.5 & 8.1 & 7.6 & 6.3 & 4.5 \\
Mityana road & 1.7 & 2.1 & 2.3 & 2.5 & 3.2 \\
Gayaza road & 6.2 & 3.8 & 3.6 & 4.6 & 4.6 \\
Bombo road & 2.9 & 2.9 & 2.8 & 2.5 & 2.9 \\
Masaka road & 5.3 & 9.1 & 9.7 & 8.8 & 3.7 \\
Entebbe road & 2.3 & 1.6 & 2.7 & 2.2 & 1.6 \\
Jinja road & 5.5 & 3.7 & 6.1 & 2.8 & 4.3
\end{tabular}

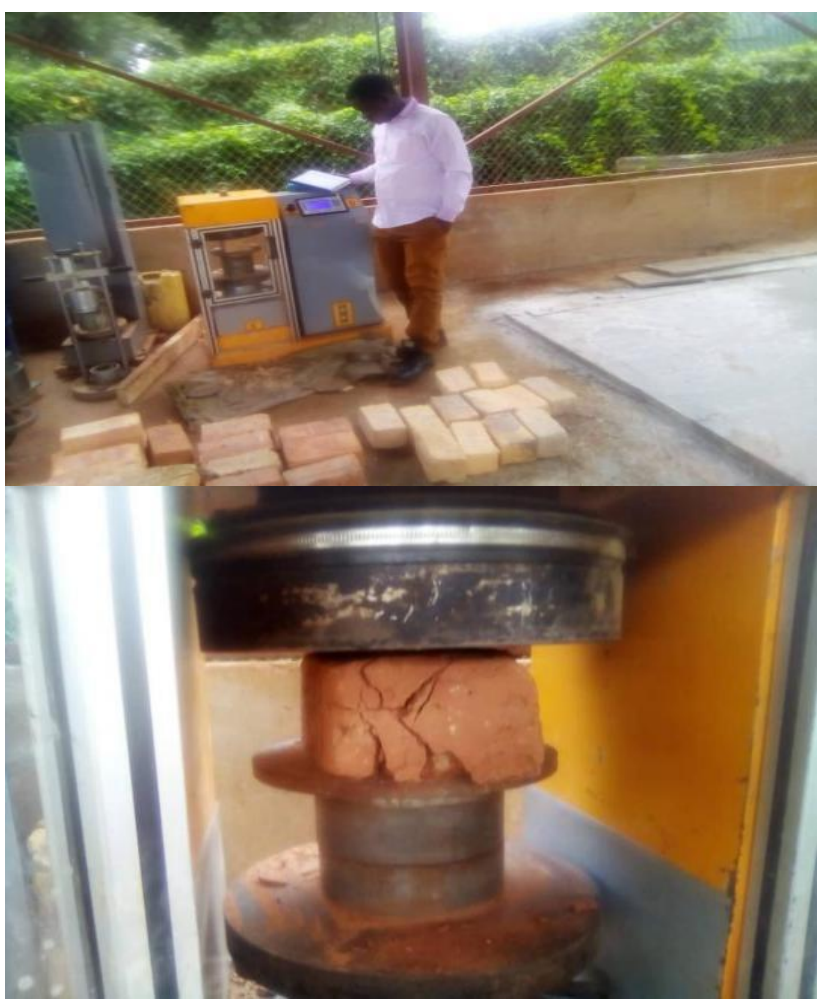

Figure :6, Compression test of burnt clay bricks

\section{ii. Variability of compressive strength of burnt clay} bricks

Using the statistical method of validating the variability of materials, it was found out that materials used around Kampala vary widely in compressive strength. Masaka road bricks had the highest deviation of $3.21 \mathrm{~N} / \mathrm{mm}^{2}$, followed by Gayaza road with $2.49 \mathrm{~N} / \mathrm{mm}^{2}$, Hoima road with $1.73 \mathrm{~N} / \mathrm{mm}^{2}$, Jinja road with $1.60 \mathrm{~N} / \mathrm{mm}^{2}$, Bombo road with $1.20 \mathrm{~N} / \mathrm{mm}^{2}$, Mityana road with $0.93 \mathrm{~N} / \mathrm{mm}^{2}$ and finally Entebbe road with $0.65 \mathrm{~N} / \mathrm{mm}^{2}$, this is clearly indicated in Figure:

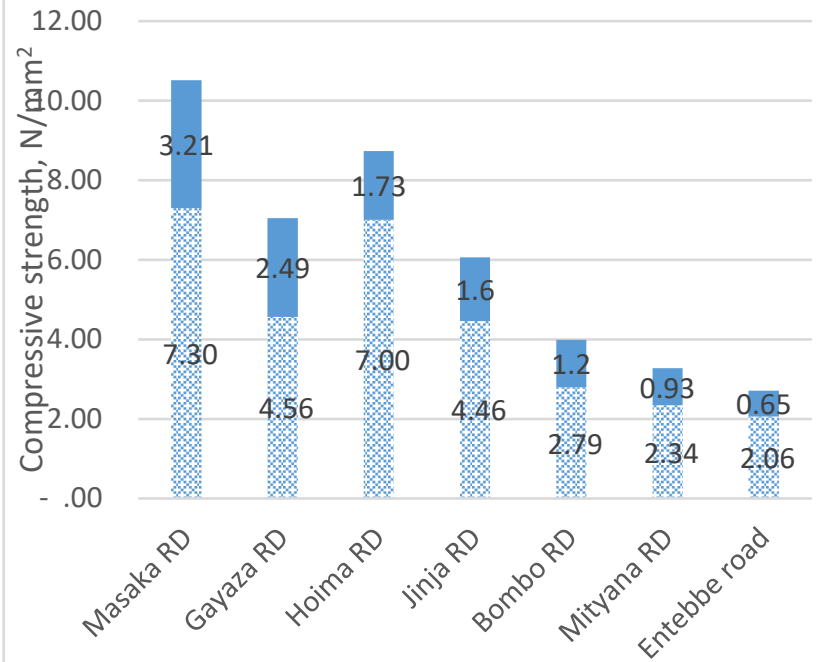

Major roads

- Standard deviation in compressive...

Figure 7: Summary of availability of compressive strength of bricks around Kampala

iii. Relationship between water absorption and Compressive strength of burnt clay bricks

From Figure 8:, test results revealed that higher percentage of water absorption results into low compressive strength.

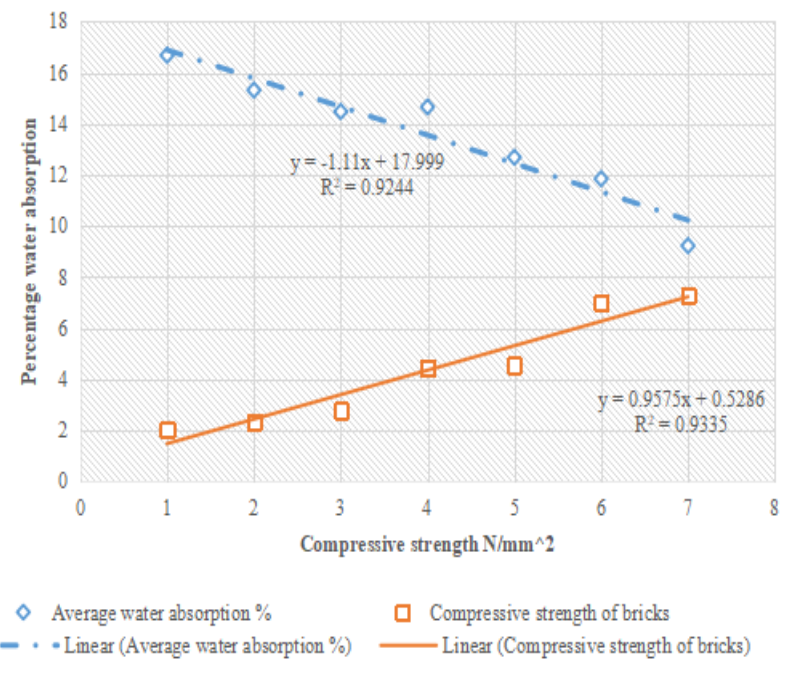

Figure 8: Relationship between water absorption and Compressive strength of burnt clay bricks

g) Determination of masonry wall strength using the test results obtained from the Laboratory

According to EN BS 1996-1-1:2005, the compressive strength of a wall is given by 


$$
f_{k}=K f_{b}^{0.7} f_{m}^{0.3}
$$

Where;

$f_{k} \quad$ is the characteristic compressive strength of masonry wall in $\mathrm{N} / \mathrm{mm}^{2}$

$K$ is a constant based on the group number and type of mortar, Table3.3, EN1996.1.1:2005

$f_{b}$ is normalized mean compressive strength of the masonry units used.

$f_{m}$ is the compressive strength of mortar in $\mathrm{N} / \mathrm{mm}^{2}$ by

The normalized mean compressive strength is given

$$
\left.\left.f_{b}=\text { [conditioning factor }\right] * \text { [Shape factor }\right] *[
$$

Declared mean compressive strength]

Declared mean compressive strength is obtained from experimental data $772-1$.

For air dried bricks, conditioning factor is $1.0, \mathrm{EN}$

$$
\begin{aligned}
& \longrightarrow \text { Hoima road } \rightarrow \text { - Mityana road } \rightarrow \text { Gayaza road } \leftarrow \text { Bombo road } \\
& \leftarrow \text { Masaka road } \rightarrow-\text { Entebbe road } \longrightarrow \text { Jimja road }
\end{aligned}
$$

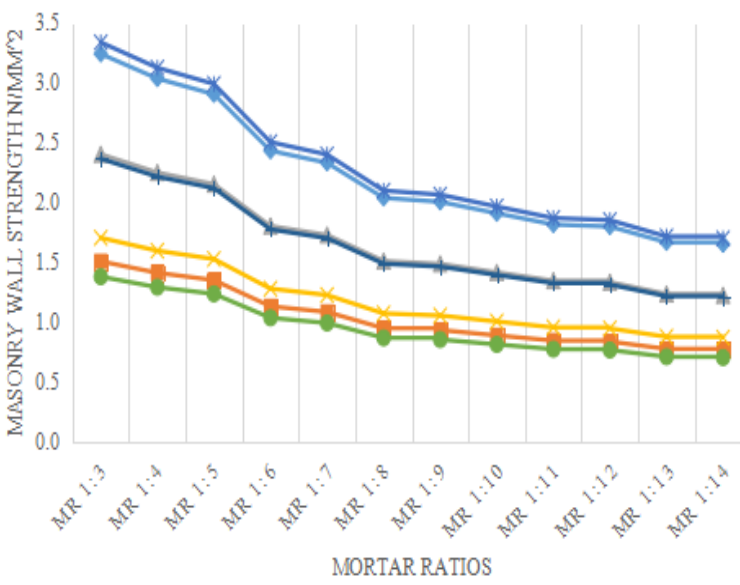

Figure 9: The compressive strength of masonry walls

Figure 9:, it is seen that when weak bricks are used with high strength mortar, the strength of the wall is found to be influenced more by the weak bricks strength. Whereas from from Table 4.4, the mortar strength varies from $17.8 \mathrm{~N} / \mathrm{mm}^{2}$ for $1: 3 \mathrm{mix}$ ratio to $1.87 \mathrm{~N} / \mathrm{mm}^{2}$ for $1: 14 \mathrm{~N} / \mathrm{mm}^{2}$ mortar ratio. The strength of the wall is considerably reduced to vary from $3.9 \mathrm{~N} / \mathrm{mm}^{2}$ for $1: 3 \mathrm{mix}$ ratios to $0.82 \mathrm{~N} / \mathrm{mm}^{2}$ at $1: 14 \mathrm{mix}$ ratio.

\section{h) Determination of wall compressive strength} constructed of field derived mortar ratios

A set of twelve walls were constructed using mortar mixes 1:7, 1:10, 1:12 and 1:14 for each of the tests. The ratios were obtained after a field survey that revealed an average volume of a wheel barrow to be $0.089 \mathrm{~m}^{3}$ and the volume of a cement bag of $0.036 \mathrm{~m}^{3}$ thus these ratios were the most applicable in the field. These were tested after 28 days using a steel loading machine at Kireka materials laboratory

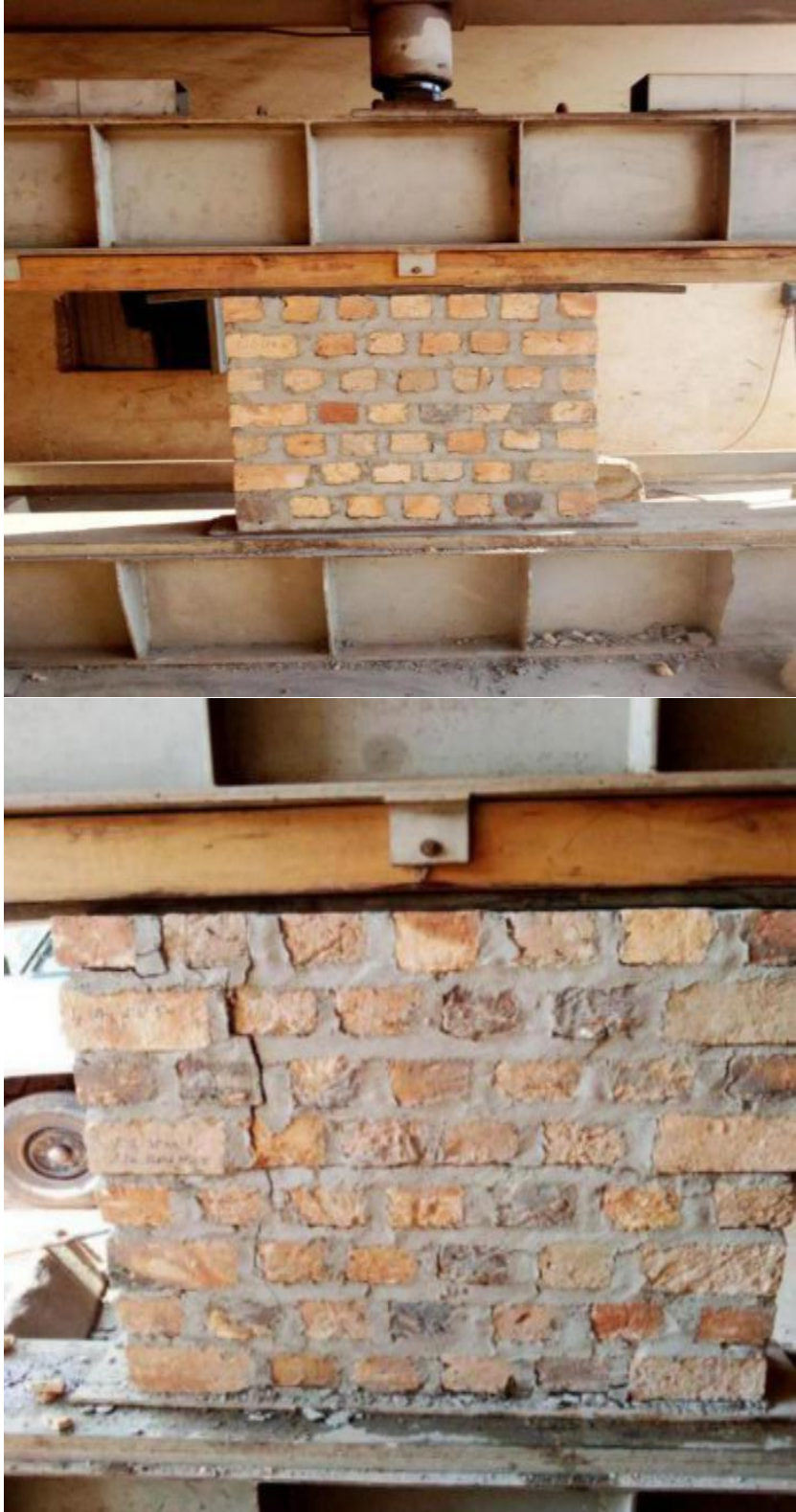

Figure 10: Wall structure $(1000 \times 1000) \mathrm{mm}$ tested and failure of the walls)

$100 \%$ of the tested walls failed due to the effect of a weaker bond strength between bricks and mortar this was evidenced by the crack patterns that followed the mortar

\begin{tabular}{|c|c|c|c|}
\hline \multicolumn{4}{|c|}{ designed wall strength } \\
\hline $\begin{array}{c}\text { Wall size } \\
(1000 \times 200) \mathrm{mm} \\
\text { Ratios }(\mathrm{FA})\end{array}$ & $\begin{array}{c}\text { Tested Average } \\
\text { Strength } \mathbf{N} / \mathbf{m m}^{2} \\
\left(f_{k t}\right)\end{array}$ & $\begin{array}{l}\text { Designed wall } \\
\text { strength } \\
\mathrm{N} / \mathbf{m m}^{2} \quad\left(f_{k d}\right)\end{array}$ & $\frac{f_{k t}}{f_{k d}} \times 100 \%$ \\
\hline MR $1: 7$ & 1.85 & 2.72 & $68 \%$ \\
\hline MR 1:10 & 1.73 & 2.23 & $77.5 \%$ \\
\hline MR 1:12 & 1.50 & 2.10 & $71 \%$ \\
\hline MR 1:14 & 1.49 & 1.93 & $77 \%$ \\
\hline
\end{tabular}
joints with less cracks through the bricks as shown in Figure 10 indicating a failure due to bond effect.

Table 3: Relationship between tested wall strength and 
From the Table 3, its observed that the compressive strength of tested walls reduced with increasing value of mix ratios as was expected. Tested results varied from $68 \%$ to $77 \%$ of the calculated designed strength of the wall.

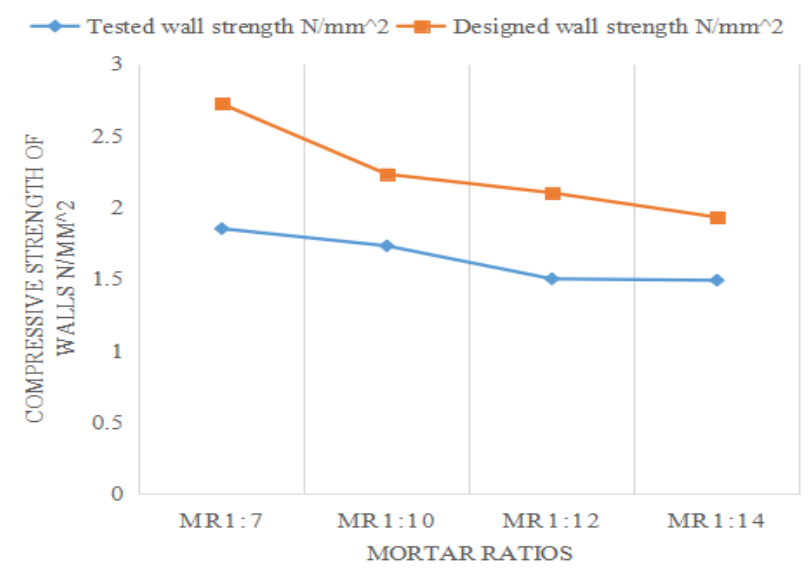

Figure 11: Tested wall strength vs designed wall strength

Table 4: Wall strength constructed of different mortar

\begin{tabular}{|c|c|c|c|c|}
\hline \multirow[b]{2}{*}{ MRl:7 } & Wall N/mm ${ }^{2}$ & 1.50 & 1.90 & 2.15 \\
\hline & Brick N/mm² & 5.63 & 8.17 & 11.73 \\
\hline \multirow[b]{2}{*}{ MRl:10 } & Wall N/mm ${ }^{2}$ & 1.46 & 1.79 & 1.93 \\
\hline & Brick N/mm² & 5.99 & 8.20 & 10.29 \\
\hline \multirow[b]{2}{*}{ MRl:12 } & Brick N/mm ${ }^{2}$ & 1.38 & 1.51 & 1.61 \\
\hline & Brick N/mm² & 6.50 & 7.69 & 8.9 \\
\hline \multirow[b]{2}{*}{ MRl:14 } & Brick N/mm ${ }^{2}$ & 1.43 & 1.46 & 1.56 \\
\hline & Brick N/mm ${ }^{2}$ & 4.7 & 6.5 & 7.71 \\
\hline
\end{tabular}

Table 4, shows the different wall strength obtained from wall units constructed of different mortar ratios using bricks of varying compressive strength, 3 samples of bricks were picked from the materials for each walling unit before construction of the unit. They were tested for compressive strength and the average found.

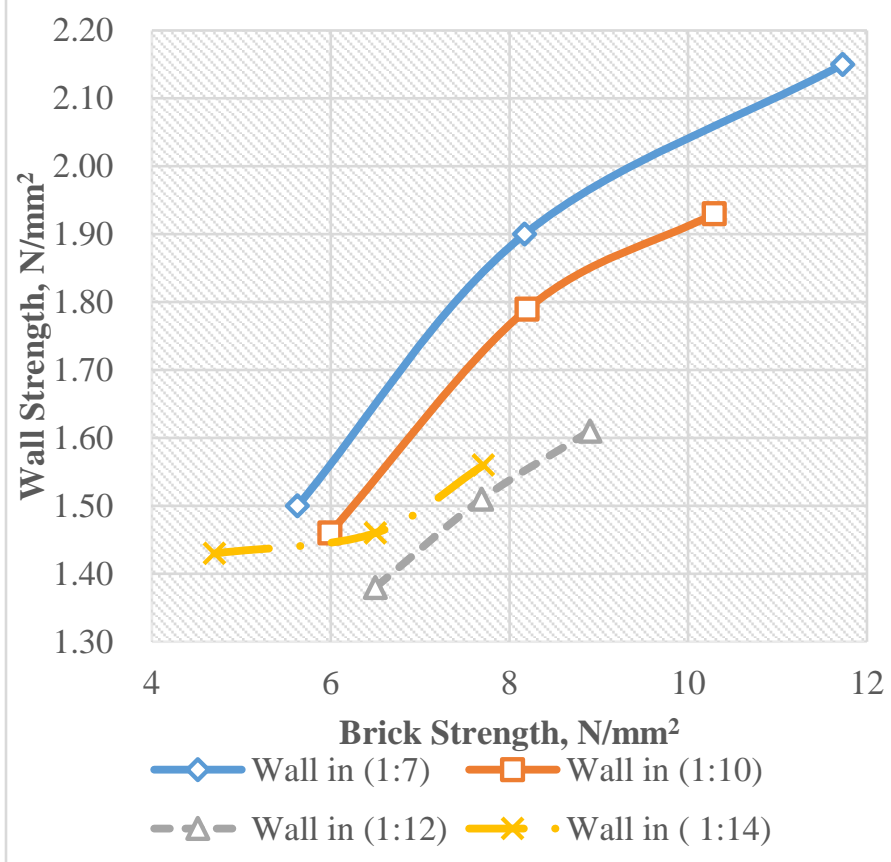

Figure: 12, Relationship between wall strength and brick strength
From Figure 12, it is seen that the lowest average brick strength is $4.7 \mathrm{~N} / \mathrm{mm}^{2}$, this resulted into wall strength of $1.43 \mathrm{~N} / \mathrm{mm}^{2}$ and the highest brick strength is $11.73 \mathrm{~N} / \mathrm{mm}^{2}$ resulting into a wall strength of $2.15 \mathrm{~N} / \mathrm{mm}^{2}$. Thus an increase in brick strength of $150 \%$ resulted into only $50 \%$ effect of brick strength and the wall strength is not so much pronounced.

\section{k) Load capacity for walls and implication factor for design}

For a wall (200mm wide x $4000 \mathrm{~mm}$ long) of mortar mix $(1: 14)$ and average brick strength of $7.0 \mathrm{~N} / \mathrm{mm}^{2}$. This would be able to support $1,192 \mathrm{KN}$.

$$
\text { Compressive strength }=\frac{\text { LoadKN }}{\text { Contactarea }} \ldots . . . .(2)
$$

The load capacity is $(200 \times 4000 \times 1.49) \times 10^{-3}=1.192 \mathrm{KN}$ It would be wrong for an Engineer to ignore this load carrying capacity and instead use bricks as infill. Exploiting the load capacity of the wall would serve as a factor of safety against differential settlements due to disturbed soils. It would ensure that the wall serves as a fuse during seismic loading.

Hence Design wall resistance,

$$
\begin{aligned}
& N_{R d}=\frac{\phi f_{k} t}{\gamma_{m}} \ldots \ldots \ldots \ldots \ldots \ldots(3) \\
& \frac{0.68 \times 1.49 \times 200}{1.0} \times 10^{-3} \\
& =0.203 \mathrm{KN} / \mathrm{m}
\end{aligned}
$$

\subsection{CONCLUSION DRAWN FROM THE THESIS}

- The actual mortar mixes used on construction sites in Kampala (Uganda) have been found to be 1:7, 1:10, $1: 12$ and $1: 14$ and not the perceived mix ratios of $1: 3$, $1: 4,1: 5$ and $1: 6$, this is due to use of un calibrated batch methods of using a $50 \mathrm{Kg}$ bag of cement to a number of wheel barrows yet their volumes are not equal.

- The strength of bricks used on constructions in Kampala (Uganda) varied greatly from $9.7 \mathrm{~N} / \mathrm{mm}^{2}$, $1.6 \mathrm{~N} / \mathrm{mm}^{2}$ averagely. This means in design the lowest strength is applicable .

- The compressive strength of mortar mix ratios used on construction sites was found to be $5.92 \mathrm{~N} / \mathrm{mm}^{2}$ for $1: 7,3.04 \mathrm{~N} / \mathrm{mm}^{2}$ for $1: 10,2.49 \mathrm{~N} / \mathrm{mm}^{2}$ for $1: 12$ and $1.87 \mathrm{~N} / \mathrm{mm}^{2}$ for $1: 14$. This is safe design since the bricks strength used varied from $7.0 \mathrm{~N} / \mathrm{mm}^{2}$ to $2.06 \mathrm{~N} / \mathrm{mm}^{2}$. And the strength of mortar should not be greater than the strength of bricks because mortar is more flexible and cracks in mortar are easy to repair.

Additionally the strength of the chain is determined by its weakest link. Thus if two materials are used it is proper and economical Engineering if their strength does not vary much.

- The average strength of walls tested varied from $1.85 \mathrm{~N} / \mathrm{mm}^{2}$ to $1.49 \mathrm{~N} / \mathrm{mm}^{2}$ averagely for mortar ratios 1:7 and 1:14 respectively. The average compressive strength of bricks used varied from $11.71 \mathrm{~N} / \mathrm{mm}^{2}$ to 
$4.67 \mathrm{~N} / \mathrm{mm}^{2}$. The resultant wall strength was much influenced by the strength of mortar, indicating that the weaker the strength of mortar the weaker the wall strength however strong the bricks may be. So, in construction the strength of mortar is key in determining the strength of the wall.

\subsection{RECOMMENDATIONS}

From the test data observations, the following recommendations have been made to support both academic and construction industry in Uganda.

a) The construction industry in Uganda should employ proper batching methods like the use of batch boxes as a way of ascertaining the actual mortar mixes used and thus improving on the durability and strength of masonry walls.

b) The construction industry should always determine the water absorption and compressive strength of masonry units during design and construction as this affects the strength of a masonry wall.

c) Structural design firms should always design masonry walls made of burnt clay bricks as load bearing walls other than providing them as infills to reduce on cost of construction, and to utilize all materials in carrying loads.

\section{ACKNOWLEDGEMENT.}

I would like to thank my supervisors, Dr. Kyakula Michael, Dr. Mugume Rogers Bangi,

My course-mates Eng.Nsubuga Jacob and Madete Robert, Kireka Materials Central Laboratory Uganda and UNRA Material Laboratory Kyambogo branch for their precious time in reading, guidance and financial assistance given throughout this research work may God bless you abundantly.

\subsection{REFERENCES}

[1] K.Mosalam,|L.Glascoe,J.Bemier.,2009. Mechanical Properties of Unreinforced Brick Masonry, Issue 10, pp. 7-8.

[2] Farraj Al - Ajmi, H. A. A. A. J. A., 2016. Strength Behavior of Mud Brick in Building Construction. Open Journal of Civil Engineering, Issue 6, pp. 482-494.

[3] Francisco M.Fernandes, P. B. a. F. C., 2009. Ancient Clay Bricks:Manufacture and Properties. ISISe, civil engineers Department, pp. 1-17.

[4] Hamid Eskandari - Naddaf, R. K., 2018. Experimental evaluation of the effect of Mix design on compressive strength of cement mortars containing cement strength class 42.5 and 52.5MPa. ScienceDirect, Issue 22, pp. 392-398.

[5] Julian Thamboo, N. J. B., 2019. Characterization and Mix specification of commonly used mortars. Research article.

[6] K.M.C Konthesingha, C. a. S., 2007. Bond and Compressive Strength of Masonry for Locally Available Bricks. The Institution of Engineers,Sri Lanka, XXXX(04), pp. 7-13.

[7] Khwairakpam sachidananda, W. V. J. s. S. L., 2017. characteristic Strength of Machine made First. International journal of Engineering Technology, Management and Applied sciences, 5(3), pp. 2349-4476.

[8] Miskir Gebre Hiwot, P. T. Q. G. K., 2017. Comparative study on compressive strength of locally produced fired clay bricks and stabilized clay brick with cement and lime. Global Scientific Journals, 5(12), pp. 2320-9186.

[9] Nassif Nazeer Thaickavil, J. T., 2017. Bahaviour and strength assessment of Masonry prism. www.elsevier.com/locate/cscm, Issue 8, pp. 23-38.
[10] NIVETHA C, J. D. R. L., 2017. Study on strength and behaviour of red mud bricks. Jr. of Industrial Pollution Control , Issue 33, pp. 1227-1230.

[11] Office, U. G. P., 1961. effect of Mortar Properties on the strength of Masonry. 20 ed. US Washington: Cyrus c.fishburn.

[12] Stephen Zsembry, G. A. a. T. M., 1982 - 2002. Determining the compressive strength of Clay bricks. C.B.P.I, pp. 308-320.

[13] Thanikasalapradeep Nagarajan, S. V. R. V. a. P. N., 2014. Experimental Approach to Investigate the Behaviour of Brick Masonry for Different Mortars Ratios. International Conference on Advances in Eingineering and Technolohy, pp. 29-30. 